\title{
RESIDÊNCIA MULTIPROFISSIONAL COMO EXPERIÊNCIA DE ATUAÇÃO INTERDISCIPLINAR NA ASSISTÊNCIA À SAÚDE DA FAMÍLIA
}

Gesilda Meira Lessa'

\section{APRESENTACÃO}

O Curso de Especialização em Medicina Preventiva e Social sob a forma de Residência Multiprofissional é oferecido pelo Instituto de Saúde Coletiva da Universidade Federal da Bahia, através do Pólo de Capacitação e Educação Permanente de Pessoal para Saúde do Estado. Visa formar especialistas em saúde coletiva cujo perfil atualmente está voltado, entre outras competências, para a atuação em gestão de Sistemas Locais de Saúde, equipes multiprofissionais e para uma com-

Destacamos, principalmente, a construção no cotidiano, através da relação entre teoria e prática nos serviços de saúde e nas comunidades, de uma postura profissional que favorece a assistência integral, a comunicação com a comunidade e estimula o controle e a participação social. preensão da visão sistêmica da família.

A procura da Residência por egressos do curso de enfermagem chama a atenção para a importância da formação multiprofissional a nível de especialização e, ao mesmo tempo, da urgência de uma revisão curricular da graduação em enfermagem, visando instrumentalizar o aluno para a atuação no mercado de trabalho emergente, voltado as novas Políticas de Saúde em implementação no país.

\section{CURSO DE ESPECIALIZAÇÃO EM MEDICINA SOCIAL SOB A FORMA DE RESIDÊNCIA - NÚME-}

RO DE EGRESSOS POR CATEGORIA. SALVADOR, 2000.

\begin{tabular}{|c|c|c|c|c|c|c|}
\hline \multirow[b]{2}{*}{ ANO } & \multicolumn{6}{|c|}{ CATEGORIAS } \\
\hline & Médico & Enfermeiro & $\begin{array}{l}\text { Assistente } \\
\text { Social }\end{array}$ & Nutricionista & Odontólogo & Psicólogo \\
\hline 1997 & 5 & 4 & 3 & 1 & 3 & 4 \\
\hline 1998 & 4 & 6 & 4 & 1 & 3 & 2 \\
\hline 1999 & 1 & 9 & 3 & - & 3 & 3 \\
\hline TOTAL & 10 & 19 & 10 & 2 & 9 & 9 \\
\hline
\end{tabular}

Fonte: Dados fornecidos pela Secretaria da Residência em Medicina Social.

Conforme o Quadro apresentado, no período de 1997 a 1999, ocorreu uma predominância de profissionais enfermeiros no corpo discente. No ano em curso, o número de vagas oferecidas para a residência foi ampliado de 20 para 30, das quais 20 para médicos e 10 para enfermeiros, odontólogos, farmacêuticos, nutricionistas, psicólogos e assistentes sociais. Essa mudança na composição das vagas ocorreu a partir da identificação pela Secretaria de Saúde do Estado da Bahia da necessidade de uma política de incentivo à formação de médicos para a assistência à saúde da família e implementação do Programa de Saúde da Família no Estado.

Considerando a importância desse tipo de experiência para o momento atual do Sistema Único de Saúde e para a integração ensino-serviço, apresentamos algumas reflexões sobre a nossa partici-

1 Professor Assistente do Departamento de Enfermagem Comunitária da Escola de Enfermagem da Universidade Federal da Bahia e Consultora para a Área de Enfermagem do Curso de Especialização em Medicina Preventiva e Social do Instituto de Saúde Coletiva da mesma Universidade. 
pação como consultora no Curso de Especialização em Medicina Preventiva e Social. Esse curso tem favorecido a atuação multiprofissional do enfermeiro, assim como das demais categorias, na perspectiva da assistência à saúde da família e permitido a cada um de seus participantes, uma crescente reflexão sobre a necessidade de novas propostas pedagógicas coerentes com a reformulação do modelo de atenção à saúde do país.

\section{ORGANIZAÇÃO E DESENVOLVIMENTO DO CURSO}

O curso tem duração de 2.348 horas, sendo que sua estrutura curricular está organizada em disciplinas que privilegiam a integração teórico-prática e atividades obrigatórias (UNIVERSIDADE FEDERAL DA BAHIA,1997). As disciplinas são elaboradas por área temática, abrangendo um leque de conteúdos e práticas em saúde coletiva e atenção primária. As áreas temáticas são: Epidemiologia em Saúde Coletiva; Educação, Comunicação e Práticas Pedagógicas Aplicadas à Saúde; Gerência de Sistemas Locais de Saúde; Ciências Sociais em Saúde e Atenção à Saúde da Família. As atividades obrigatórias apresentam-se organizadas como: Atividade Integrada; Pesquisa Orientada; Estágio em Serviços I e Estágio em Serviços II.

As atividades teóricas são articuladas com atividades práticas e com estágios supervisionados. Estes são realizados em unidades básicas de saúde dos distritos sanitários de Salvador, municípios onde forem constatadas condições satisfatórias para o desenvolvimento das práticas, Diretorias Regionais de Saúde e no nível central de Secretarias Municipais de Saúde. Abrangem atividades práticas nas áreas de planejamento, programação local, vigilância em saúde, comunicação e práticas pedagógicas em saúde e atendimento de pacientes em nível ambulatorial e domiciliar ligados a serviços locais de saúde. Essas práticas são acompanhadas, supervisionadas e avaliadas pelo grupo de docentes das disciplinas e profissionais de nível superior dos serviços utilizados como campo de prática.

Além do grupo de docentes e supervisores, a Residência conta com a participação de consultores de várias categorias profissionais que colaboram para o estímulo dos discentes na busca de alternativas aos problemas identificados nos territórios, famílias e instituições em que atuam nas suas atividades práticas.

\section{COMPREENDENDO AS HABILIDADES PROPOSTAS}

Como forma de subsídio para a intervenção multidisciplinar da equipe de saúde, a Residência tem investido em áreas ainda pouco exploradas nos cursos de graduação da área de saúde (UNIVERSIDADE FEDERAL DA BAHIA, 1997):

- Utilização dos indicadores de saúde na análise de situação de saúde de grupos populacionais específicos, diagnóstico de saúde da comunidade, planejamento e avaliação dos serviços de saúde, medidas de promoção à saúde, prevenção de doenças e agravos, assim como de monitoramento dos grupos de maior risco;

- Compreensão do processo educativo e da comunicação social em saúde, facilitando as mudanças nas práticas de promoção e elevação da qualidade dos serviços de saúde prestados à população;

- Aplicação de técnicas e instrumentos de gestão estratégica para o trabalho dos profissionais, na perspectiva da integralidade e da intersetorialidade das intervenções, com ênfase no planejamento e programação, na condução de processos de trabalho, na negociação dos distintos interesses representados no nível local e nas técnicas de administração de recursos;

- Explicitação dos condicionantes econômicos, políticos, culturais e psicossociais do processo saúde-doença, assim como as implicações de adotar-se a família como objeto de intervenção;

- Adoção da família como objeto de intervenção em saúde, considerando-a enquanto contexto diversificado de desenvolvimento humano;

- Compreensão da família como um grupo social com peculiaridades próprias que demandam alternativas de intervenção baseadas na cooperação, co-responsabilização e respeito mútuo; estabe- 
lecer inter-relações entre estrutura familiar, redes de apoio à família e adesão à programas e ações de saúde; identificar práticas e estratégias assistenciais mais sensíveis às características do ambiente social, perfil sociocultural, necessidades sociais e sanitárias da comunidade e das famílias que nela vivem;

A construção dessa prática profissional está centrada na intervenção da equipe multidisciplinar, a partir de estratégias assistenciais centradas na vigilância à saúde e assistência à saúde da família.

\section{MÉTODOS E INSTRUMENTOS DE INTERVENÇÃO FAMILIAR COMOFORMA DE REVER CONCEI- TOS, VALORES E PRÁTICAS NA EQUIPE MULTIPROFISSIOONAL}

Abordaremos, nesse artigo, alguns aspectos que consideramos diferenciados e enriquecedores do processo de consultoria experienciado e que englobam dois momentos: Técnico e de Discussão de Casos (UNIVERSIDADE FEDERAL DA BAHIA,1997). O Momento Técnico foi realizado através da leitura de textos e aprofundamento de temas em subgrupos. O Momento de Discussão de Casos, selecionados a partir das atividades práticas desenvolvidas em determinada micro área da comunidade, através da demanda expontânea ou por seleção dos residentes em visitas domiciliares, envolve a utilização de instrumentos como a "História de Vida" e o "Protocolo de Intervenção Familiar", facilitadores de uma abordagem sistêmica voltada para os indivíduos, família e comunidade.

A coleta da "História de Vida" apresenta-se como instrumento de aprofundamento da relação entre o profissional de saúde e os indivíduos que procuram os serviços, além de facilitar a aproximação desse profissional ao contexto familiar, assim como a intervenção da equipe multidisciplinar frente aos problemas relatados.

O "Protocolo de Intervenção Familiar" inclui a realização pela equipe multidisciplinar de um conjunto de procedimentos como o diagnóstico biopsicossocial, construção do familiograma, classificação da família e dinâmica familiar, através do gráfico das relações familiares observadas, levantamento dos problemas por indivíduo e família, além do planejamento, desenvolvimento e avaliação das ações propostas, segundo os problemas individuais, da família e coletivos da micro área onde residem.

A apresentação e discussão desses instrumentos mostrou a importância da intervenção interdisciplinar (Patrício, 1996) que embora ainda em desenvolvimento, viabiliza a intervenção sobre os problemas levantados, trabalhando a família como um sistema aberto (Linhchin; Fishman,1990) em interação com sistemas extrafamiliares (meio ambiente - comunidade).

\section{CONCLUSÃO}

Nossa experiência pessoal de consultoria no Curso de Especialização em Medicina Preventiva e Social, oferecido pelo Pólo de Capacitação e Educação Permanente de Pessoal para Saúde da Família (Instituto de Saúde Coletiva da Universidade Federal da Bahia), apesar de limitada em relação a globalidade do curso, tem indicado alguns pontos demarcadores de uma nova prática profissional, diferenciada da ainda hegemônica nos serviços de saúde.

Essa prática tem sido propiciada através do estímulo à atuação interdisciplinar da equipe multiprofissional, da capacitação dos profissionais na utilização do instrumental da clínica, da epidemiologia e do planejamento no enfrentamento dos problemas de saúde em um território delimitado. Destacamos, principalmente, a construção no cotidiano, através da relação entre teoria e prática nos serviços de saúde e nas comunidades, de uma postura profissional que favorece a assistência integral, a comunicação com a comunidade e estimula o controle e a participação social.

Consideramos que esse tipo de prática profissional necessita ser institucionalmente fortalecida, através do estabelecimento pelo governo de políticas setoriais, intersetoriais e de recursos humanos que realmente propiciem a reorganização e uma nova estruturação dos serviços de saúde. Apresentamos, também, a expectiva de maior investimento na adequação desse perfil profissional em formação e na construção do conhecimento interdisciplinar, identificação de competências gerais e específicas por categoria nesse novo contexto. 
Nesse contexto, identificamos a necessidade de estudos posteriores sobre a intervenção multiprofissional do enfermeiro de forma integral, contínua e de qualidade à população no nível domiciliar e ambulatorial,.

\section{REFERÊNCIAS BIBLIOGRÁFICAS}

LINHCHIN; FISHMAN. Técnicas de Terapia Familiar. Porto Alegre: Artes Médicas, 1990.

PATRíCIO, Zuleica Maria. Administrar é trabalhar com gente...A interdisciplinaridade no processo de cuidar indireto através da educação. Revista Texto e Contexto, Florianópolis, v.5, n.2, p.55-77, jul./dez. 1996.

UNIVERSIDADE FEDERAL DA BAHIA. Pólo de capacitação e educação permanente de pessoal para saúde, Instituto de saúde coletiva. Projeto do Curso de Especialização em Medicina Preventiva e Social sob a forma de Residência. Salvador, 1997. 